\title{
Materials for a Non-Steady-State World
}

ROBERT E. SCHAFRIK

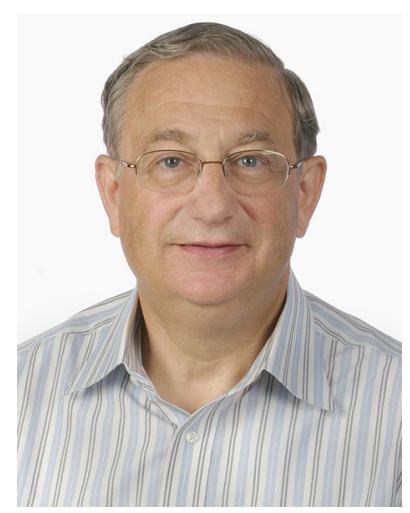

DOI: $10.1007 / \mathrm{s} 11663-016-0655-4$

(C) The Minerals, Metals \& Materials Society and ASM International 2016

\section{INTRODUCTION}

THIS is the 44th lecture in the series of "Materials and Society." The first lecture was presented in 1971 by Prof. Harvey Brooks, Harvard University, and was titled "Materials in a Steady-State World." $[1]$ The focus of Professor Brook's remarks was on sustainability and economical use of materials in design with the thought that a steady state would eventually be reached between consumption of materials by industrial societies and the availability of mineral resources. He posited that technical progress in three areas would be necessary in order to attain this desired state of affairs, anticipating that the world would continue to industrialize and thus consume ever more resources: (i) More ore bodies would be

ROBERT E. SCHAFRIK, Sr., formerly General Manager with the Materials and Process Engineering Department, GE Aviation, Evendale, $\mathrm{OH}$, is now retired. Contact e-mail: robert.schafrik@yahoo.com

Robert E. Schafrik, Sr. retired from GE Aviation in April 2014 after serving for 17 years as general manager of Materials and Process Engineering. This department develops and qualifies the materials used in GE's aero-engines and their land and marine derivatives. Prior to GE, for seven years he was staff director for the National Materials Advisory Board at the National Research Council (NRC). Prior to this, Bob was vice president of research and development for Technology Assessment and Transfer, Inc. for three years. He served in the U.S. Air Force for 20 years in a variety of R\&D and advanced aerospace system acquisition capacities. Bob chaired the NRC's National Materials and Manufacturing Board 2012-2015. He is a Fellow of ASM International and is a member of the National Academy of Engineering. He received ASM International's William Hunt Eisenman Award and GE Corporate's Edison Award. Bob has a Ph.D. in metallurgical engineering from Ohio State University, a M.S. in Information Systems from George Mason University, a M.S. in Aerospace Engineering from the Air Force Institute of Technology, and a B.S.in Metallurgy from Case Western Reserve University.

Article published online March 31, 2016. discovered, and the extraction fraction of metals from them would be improved; (ii) Substitute materials would be developed to replace those that become scarce; and (iii) New technologies would improve the recycling of materials.

The title of this talk, "Materials for a Non-Steady-State World," is aimed at a different theme: expectations for continued improvement in the functionality and quality of products continue to rise non-linearly as the effects of progress are observed and experienced. Since materials are an essential ingredient of all physical products, the challenge to the materials community is to continue to develop and implement improved materials solutions that directly impact the quality of life at a much faster pace than a typical 10-year timeline in order to better align with the typical 3- to 5 -year product development timeline. Furthermore, societal expectations are that the improved material solutions will meet all requirements so that performance of the end product is maintained. Importantly, accelerated materials development can offer an attractive value proposition for the customer and the manufacturer.

These considerations have been a driving force for the US government's Materials Genome Initiative. ${ }^{[2]}$ The Materials Genome Initiative (MGI) is a multi-agency initiative designed to create a new era of policy, resources, and infrastructure in the effort to discover, produce, and deploy advanced materials twice as fast. In line with MGI, Integrated Computational Materials Engineering (ICME) has the vision of integrating information across length and time scales for all relevant materials phenomena and enables concurrent analysis of manufacturing, design, and materials for a complete end product. ${ }^{[3,4]}$

Much effort has been expended in the development and verification/validation of computational models, and supporting databases that can estimate materials 
properties, and can assist in the development of optimal materials processing routes. Many presentations at materials conferences address some aspect of ICME and the MGI. Indeed, there are entire technical conferences now dedicated to both topics.

There are three strategic elements that are necessary to achieve more rapid commercial application of new materials in addition to computational tools. Consider that even if computational models were perfect, reduced implementation time is not a given. These three additional elements can significantly reduce the time and effort required to insert new materials into products:

1. Forward-looking materials strategies that contain a feasible menu of materials advancements that could add significant value to an application of interest.

2. Materials development process with a strong application focus so that the technology is championed by those responsible for materials implementation decisions. Development and implementation cannot be performed as completely separate tasks for an accelerated program.

3. Creation and fostering of high-performance teams to execute materials development.

For simplicity, the term "material" is used instead of "material system." In reality, an integrated material system must be developed for a particular application; this includes the base material, the necessary environmental and tribological coatings, the suite of processes employed to produce and inspect the material, and methods of joining with other structural elements. Also, to avoid redundant wording, the term "material" is also meant to include new process developments, such as additive manufacturing.

\section{DRIVING FORCES PROMOTING AND TEMPERING TECHNOLOGY CHANGE}

The primary impetus for change in materials technology is responding to the competitive landscape; a manufacturer can enhance its position in the marketplace by offering a product that is superior to those of the competition. Design changes are desired that cost-effectively increase customer value, such as greater performance, better safety and reliability, lower price, and reduced maintenance burden. Design changes could also result in reduced manufacturing cost so that the manufacturer's operating margin can be increased, freeing up resources for additional product development.

New designs, or changes to a current design, have the risk that not all the changes will perform as intended, with the consequence that the competitive position could worsen. Thus, understanding the possible risks and the resources required for risk mitigation strategies can temper the go-forward decision for a new material. Some of the risks that are typically considered include the following:

- Materials and process development may not be completed on time; e.g., difficulty in scaling up to produce full-scale components from subscale experi- ence. These problems are usually resolved over time, but the lament that one "cannot invent on a timeline" is unfortunately true, so that the completion date could be uncertain.

- Not all critical requirements may be satisfied by the new material, causing a debit in performance, and possibly a redesign of the system to accommodate a material property shortfall. For instance, for applications outside of past experience, additional critical materials requirements that were not previously foreseen may be discovered during testing or early in-service operation. Another potential cause of a property shortfall is not having full understanding of the process control limitations for full-scale processing.

- Accelerated tests may not properly simulate longterm materials performance in the actual service environment.

- The supply chain may require additional time to scale up for production quantities that meet the necessary delivery rate, quality, and cost metrics.

The conventional timeline for introducing a new material is often stretched out to deal with risk items. The development timeline can be divided into four cases. ${ }^{[5]}$ In this context, a critical material application is one in which a material failure would cause significant loss in functionality such that the end product would not work properly, and have to be repaired or replaced.

I. Modification of an existing material or process for use in a non-critical application-2 to 5 years.

II. Modification of an existing material or process for use in a critical application, such as a critical structural component -4 to 6 years.

III. Insertion of a new material into a critical application-10 to 12 years.

IV. Introduction of a new material class or a new processing route-up to 20 years and beyond.

As will be described in subsequent sections, for Cases I, II, and III a 50 pct reduction in the development time for insertion into an application is potentially possible at relatively low risk. Cases I and II would have a substantial amount of information about the material, the supply chain would already exist, and the business case for insertion could be developed with confidence. For case III, a great deal of data will exist; it may not include full-scale production though, so the risk of insertion will be higher. Applying a new material in an existing application is lower risk since the requirements that the material must meet are known. Inserting a new material into a newly designed application is more challenging since all the requirements may not be known until product testing is accomplished, and the ability of the production process to achieve the requirements of the fully designed components can be assessed. This is especially true of highly complex systems, such as jet engines, in which all the design parameters cannot be accurately predicted, with the consequence that the material properties may have to be adjusted as a result of what is learned during product development testing. ${ }^{[6]}$

Case IV involves the development and application of a new material class, such as an intermetallic structural 
material, or a completely new processing route, such as additive manufacturing. There are multiple options that must be investigated, and multiple application opportunities that must be sorted out. So a 50 pct reduction in development time would be difficult to achieve unless a costly project is launched to concurrently explore multiple options.

The titanium aluminides are an example of Case IV that took longer than 20 years to be applied. (The development time would have been much longer without the pioneering work accomplished by the Air Force Research Laboratory's Materials and Manufacturing Directorate, the Office of Naval Research, and the Structures and Materials Division at the NASA Glenn Research Center.) These materials had the attractive promise of replacing nickel-based superalloys in certain applications without loss in performance at half the weight. On the other hand, they also possess much less than half the ductility at room temperature, so new design rules had to be created to avoid the possibility of cracking during processing, installation, and operation at lower temperatures. Plus the supply chain had to be established, from the synthesis of the material to specific processing steps. Material and process specifications were developed and implemented such that the new material could be consistently produced to technical and cost requirements.

GE began its investigation of the titanium aluminides in the 1980s. US patent 4916028A was granted in 1990 for a chemistry that provided a balance of mechanical strength and ductility/fracture toughness. The alloy that best survived the gauntlet of development tests was Ti-48Al-2Nb-2Cr. Many potential applications for TiAl in a jet engine were considered. GE focused on the large turbine blades since the weight savings would be considerable; this translates into improved fuel efficiency. A new design approach was developed to incorporate fracture mechanics analyses beyond what is typically done for conventional nickel-based superalloy turbine blades. Also, the casting suppliers were challenged to establish TiAl turbine blade casting processes capable of meeting rate production at the necessary quality levels. The raw material suppliers had to scale up from providing a few thousand kilograms of ingot material per year to $450,000 \mathrm{~kg}$ per year. ${ }^{\text {[] }}$

Figure 1 shows the cast TiAl, GE 48-2-2, turbine blade uninstalled and installed in the last stage of the low pressure turbine rotor of a GEnx engine. This is the first FAA certified structural intermetallic material application. The figure also lists the system-level certification requirements that the $\mathrm{TiAl}$ turbine blade satisfied in gaining certification. It is challenging to convert these system-level requirements into specific material properties, so these certification tests can result in surprising results. The TiAl turbine blade past these tests without difficulty. ${ }^{[7]}$

The TiAl low pressure turbine blades have performed flawlessly in-service. The Boeing 747-8 entered revenue service in 2011; it is powered by four GEnx-2B engines that contain one stage of TiAl turbine blades. The Boeing 787-8 entered revenue service in 2012; it is powered by two GEnx-1B engines, each of which contains two stages of TiAl turbine blades. Consequently, each airplane model flies with 400 TiAl turbine blades, As of the fall of 2014, 100,000 TiAl turbine blades had entered service in 175 aircraft encompassing 500 engines; altogether these turbine blades had accrued 2.5 million hours without failures. So the long, drawnout materials development process does work. An accelerated development program would have allowed benefits to be realized much sooner if the monetization of the benefits was greater than the development and scale-up costs while considering the probability of success for a first application of a new class of materials.

A reasonable goal for Case IV materials and processes would be reducing the development time by half once the material chemistry/microstructure/architecture has been well developed and characterized, or a new process has matured to the point of consistently producing a desired output, such that an explicit application can be targeted.

\section{STRATEGIC FOUNDATIONS FOR ACCELERATING R\&D AND DEPLOYMENT OF NEW MATERIALS}

Over the course of the past decade, GE Aviation has introduced a large number of new materials and processes as it refreshed its family of aero-turbine engines and responded to demands of the marketplace. The new materials and process technologies included the following:

- TiAl for cast turbine blades.

- Advanced high temperature superalloy for single crystal high pressure turbine blade alloy.

- Advanced high temperature superalloy powder alloy for turbine disks.

- Ceramic matrix composite, $\mathrm{SiC} / \mathrm{SiC}$, for turbine shrouds.

- Additive Manufacturing to produce advanced turbine combustor fuel nozzles.

- Polymer composite flowpath spacer, designed to "rotating part standards"; i.e., same standards as used for turbine disk design.

- Light weight carbon fiber composite for fan cases.

- Advanced tribological coatings for compressor vanes and blades.

- GE1014 ultra high torsional strength steel for fan shafts.

- NiAl for turbine blade coating.

- Advanced solid state joining for titanium and superalloy components.

- Low rhenium content, René N515 alloy for single crystal turbine blades.

- High temperature cast and wrought alloy, René 65, for turbine rotating and static structure applications.

This significant development activity provided opportunity to hone the approach to insert new materials into applications. There were four necessary elements: modeling and simulation of the material and processing, forward-looking materials strategy, robust management of the materials development process, and formation of 
high-performance development teams. Since much is being written about modeling and simulation, the remainder of this paper will focus on the last three elements.

The accelerated programs, undertaken to meet a critical business need, were distinguished from those conducted by the standard development process, by the degree of concurrency in the tasks, rather than merely performing each sequential task faster. Thus the crux of the accelerated process was to direct the concurrency with a deliberative, thoughtful method.

\section{A. Forward-Looking Materials Strategy}

At the strategic level, aerospace applications continually demand new materials that are lighter weight, possess higher operating temperature capability, and have increased durability in the service environment. And not only must a new material excel in at least one of the desired properties, it must also have a practical balance of all the other properties required for an application. Therefore, establishing a well-defined method for highlighting and assessing promising new materials and process directions is important for building a storehouse of practical advanced materials technology ideas.

The first step in constructing a storehouse of advanced materials ideas is to simply list the high level materials and process technologies of interest in the application domain. For aerospace, this list would typically include nickel-based superalloys, titanium, high strength steels, polymer matrix composites, ceramic matrix composites, anti-corrosion coatings, additive manufacturing, solid state welding, etc. It is usually best to organize these technologies by material or process type rather than by application, such as "next generation turbine blade"; normally a design engineer selects the material for an application, and one of the goals of materials experts is to provide options for the designer. For instance, a turbine blade could be made from a superalloy, a titanium aluminide, or a ceramic matrix composite, each of which would have a separate materials development strategy. For strategies focused on processes, such as solid state joining and additive manufacturing, multiple materials would be included. For example inertia welding of titanium and nickel alloys could be involved in assessing new directions for solid state joining.

For each category of technology, the current state of the art is assessed, including current known research directions, as well as relevant intellectual property (IP) - licensing technology of interest could save considerable time and resources. Then materials experts, together with other experts, use their inventive genius to explore new technology directions, potential benefits and anticipated challenges. It is important to understand the entitlement level for the materials and processes of interest, which sets an expectation regarding the point of diminishing returns. For example, highly alloying a superalloy can not only improve strength, but it can also increase the tendency for macro-segregation, lower incipient melting point, and increased density.
An important step in the process is to identify future priority applications for each technology idea, together with the most important requirements that are provided by design engineers and customer requests. Understanding the gaps between the currently available material solution and the potential additional capability offered by a new material is essential to construct a program plan that demonstrates feasibility and provides necessary inputs into the value case analysis. This usually requires accomplishing a preliminary design of a specific component using anticipated material properties. Prediction of properties using computational tools, supplemented by selected small laboratory-scale testing, can add to the confidence level of what properties could be achieved. If a design engineer concludes that the estimated properties are of interest, a development plan is outlined. It includes preliminary work to validate the projections, and a roadmap for full development that leads to insertion in a specific application. The roadmap could include a partnering strategy.

\section{B. Robust Management of Materials Development}

The opportunities highlighted in the materials strategy plan that proceed into the next phase of development require the agreement by the design organization and the engine line business manager. The primary considerations are as follows: the materials technology would add significant value to a specific application, and the development cost and risk are manageable within the expected timeline. The targeted application could be in an existing aero-engine or one that is slated for development. Those opportunities not selected for scale-up remain on the materials strategy list for further investigation, except for those for which the determination is that there no potential application in the foreseeable future.

There are three phases to materials development: (i) Establishment of Feasibility, (ii) Demonstration of Applicability, and (iii) Maturation and Scale-up. The development time is measured from the start of Feasibility to the insertion of materials or process technology at the end of the Maturation phase. Milestones that measure progress follow the framework of the Technology Readiness Levels (TRL) and Manufacturing Readiness Levels (MRL). ${ }^{[8,9]}$ Accelerated programs have a degree in concurrency for these phases, while standard programs do each phase sequentially. A schematic of concurrency is depicted in Figure 2.

Each development program establishes the level of concurrency appropriate for that program. Important factors for determining the appropriate degree of concurrency include the following: an assessment of the benefit level if the development is successful, the degree of risk for doing some tasks concurrently, and the desired insertion date for the technology. In the past, the materials development timeline was somewhat disconnected from the product development timeline; materials development took much longer than product development, and consequently many opportunities to insert new materials and processes went astray. ${ }^{[10]}$ 


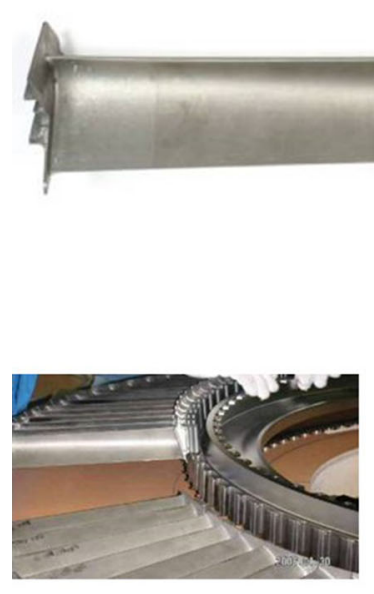

\section{Aero Engine Certification \\ Requirements}

- Performance

- Operability

- Crosswind

- Over Temperature

- Cyclic Endurance

- Bird Ingestion

- Fan Blade Out

- Hail Ingestion

- Water Ingestion

- Icing

- $\quad$ LPT Stress

- Triple Redline Engine Test

Fig. 1-Gamma TiAl turbine blade and certification requirements.



Fig. 2-Concurrency of material development phases.

Since the design engineer selects the materials and processes to implement the design, a decision was made at GE to involve the design engineer in the leadership of the materials development program from the beginning. Previously, the design engineers were briefed as key milestones were achieved. This process did not provide a sufficient amount of interchange between the design team and the materials development team for an accelerated program. Design requirements evolve, materials property data are constantly being generated, materials composition can change slightly with time, etc. Having the lead design engineer as part of the leadership team eliminated communication gaps, and led to much smoother insertion of the materials technology.

The Feasibility Phase has the objective of demonstrating the feasibility or suitability of a new material or process for a selected application. During this phase, the following main activities are accomplished:

- The technology concept is refined using computational tools and the knowledgebase of experts. This includes developing the full suite of requirements for applications of interest in partnership with design engineering. Significant challenges are explicitly identified, along with mitigation strategies.
- Initial feasibility of the technology is confirmed, usually through a combination of further analyses and proof-of-concept experiments. The test results are compared to analytical predictions to gauge the accuracy of the predictions and provide insight into areas for further improving the prediction tools and methodology.

- Manufacturing methods and production cost are assessed in order to validate the value case for the project.

The Demonstration Phase generates data to characterize the risks, costs, and benefits on inserting the technology into a particular application. The primary goal is that the product decision-makers will have sufficient information to make informed decision regarding proceeding with full-scale development. The main activities during this phase include as follows:

- Demonstrate capabilities in a portfolio of laboratory tests, component rig tests, and engine tests. Complete a design incorporating the material and validate the requirements. Manufacture components using production-scale processes.

- Develop manufacturing processes and procedures. Identify long lead items and key supply chain elements.

The Maturation Phase incorporates the new material into the design of a particular component, and produces the component using full-scale production equipment. The following activities occur during this phase:

- Generate a complete set of material property data using specimens extracted from production hardware.

- Establish the processing details, including specifications and standards.

- Qualify the material, and certify the product application with the appropriate aviation authority, such as the Federal Aviation Administration (FAA).

- Monitor in-service performance after implementation to verify that the material meets expectations. If all 
requirements are not being met, a development effort can be targeted at providing the necessary upgrade.

Figure 3 shows that the product creation cycle employs the same three phases as the technology creation development cycle: Feasibility, Demonstration, and Maturation. In this depiction, the technology creation phases are sequential; however, the phases would have concurrency for an accelerated program. A cardinal rule of product development is that only mature technologies from the materials Maturation phase should be considered for insertion into the product's Demonstration phase. Thus, materials technology must necessarily lead the product creation cycle together with substantial interaction with the product creation team. This reality is a fundamental reason that having a well-prepared materials strategy is important.

\section{Formation of High-Performance Development Teams}

Development programs necessarily involve a great deal of interaction between people with different expertises, different skill levels, and different roles. A passionate, knowledgeable, small, highly focused high-performing team is crucial to the success for any development effort, especially for an accelerated program. Many different materials, manufacturing, system engineering, and design specialists must work together seamlessly toward a challenging common objective under a defined process that requires each team member to contribute complementary expertise. The team leader and senior business leaders have the crucial role of removing obstacles for the team, providing necessary resources, communicating the importance of progress toward the goal, and holding the team accountable for the results. During the course of a development program, many issues are worked across the disciplines. Usually these issues are not confined to a single discipline, but have multiple interactions. The team's goal is to quickly and constructively address these issues. ${ }^{[11]}$ Upon completion of the objective, the team is disbanded and the people re-assigned to other projects.

Attracting people to serve with enthusiasm on these teams has not been difficult. Consider that there are three behavioral realities that affect the behavior of people: historical reality (cultural background, education, training, inherent personality, etc.); current reality (personal gain, peer pressure, habit, loyalty, expectations, optimism, etc.): and anticipatory reality (dreams, visions, utopian ideas). Of these three realities, anticipatory reality is by far the most important, with more than twice the combined influence of historical reality and current reality. ${ }^{[12]}$ Anticipatory reality is forward-looking. Most people gain great satisfaction in working on technology that is successfully implemented within a reasonable amount of time. In the past, with the long development cycle and uncertainty in the end application, a materials developer could specialize on a single technology for an entire career, such as titanium aluminides, with the hope that the technology would eventually be selected for an engine application. Under the new approach, the technology is targeted at an application early in the development cycle in partnership with design engineering. Thus, people skilled in materials science, development, and application now have the expectation that the new materials technology could be inserted into an application within a few years. This allows the opportunity to work on multiple materials technology developments over a career. Such a prospect is very attractive to many materials scientists and engineers, as well to other team members.

\section{ACCELERATED MATERIALS DEVELOPMENT PROGRAMS}

In recent years, GE Aviation has conducted several accelerated materials development programs, using the methods described in this paper. Two of the programs are discussed below. Both of these examples replaced existing materials in production engines; the time from start of the development program to engine certification by the FAA was less than half the traditional time.

The first example is a new low rhenium content single-crystal turbine blade alloy, René N515. The motivation was a strategic concern on the long term availability of rhenium. The second example is a new high-temperature cast and wrought turbine disk alloy, René 65 , that could replace a powder metallurgy disk alloy that had to be iso-thermally forged; with the large increase in engine sales, a look-ahead in iso-forge industrial capacity caused concern that major equipment investments would have to be made in the near future to avid constraining disk production capacity.

\section{A. Low Rhenium Content Turbine Blade}

Rhenium has been found to greatly strengthen nickel-based superalloys at high temperature, and as such has been a widely used alloying addition to generation two single-crystal superalloy blades that are employed in the first stage of the high-pressure turbine. Rhenium is very rare metal. There are no direct ore deposits of rhenium; it is produced as a byproduct during copper and molybdenum refining. For more than a decade, its price was less than $\$ 2000 / \mathrm{kg}$. In 2006 its price doubled; by 2008 the price had increased to five times the baseline amount. GE Aviation did an analysis to determine the root cause of the price increase. It was concluded that the usage of rhenium in turbine blade superalloys was approaching the yearly production volume of the element-so the price increase was supply-demand driven. Furthermore, extrapolation of the rhenium usage trend line indicated that GE's use of rhenium alone would exceed the world's available supply within a few years if no actions were taken.

Consequentially, a major program was instituted immediately to work with customers and suppliers to recycle all rhenium-containing alloys. Another action was to substitute other alloys in applications that did not require the strength of the rhenium-containing alloys (previously, standardizing on a few alloys was desired by the supply chain). Finally an assessment was made regarding the development of a new alloy 


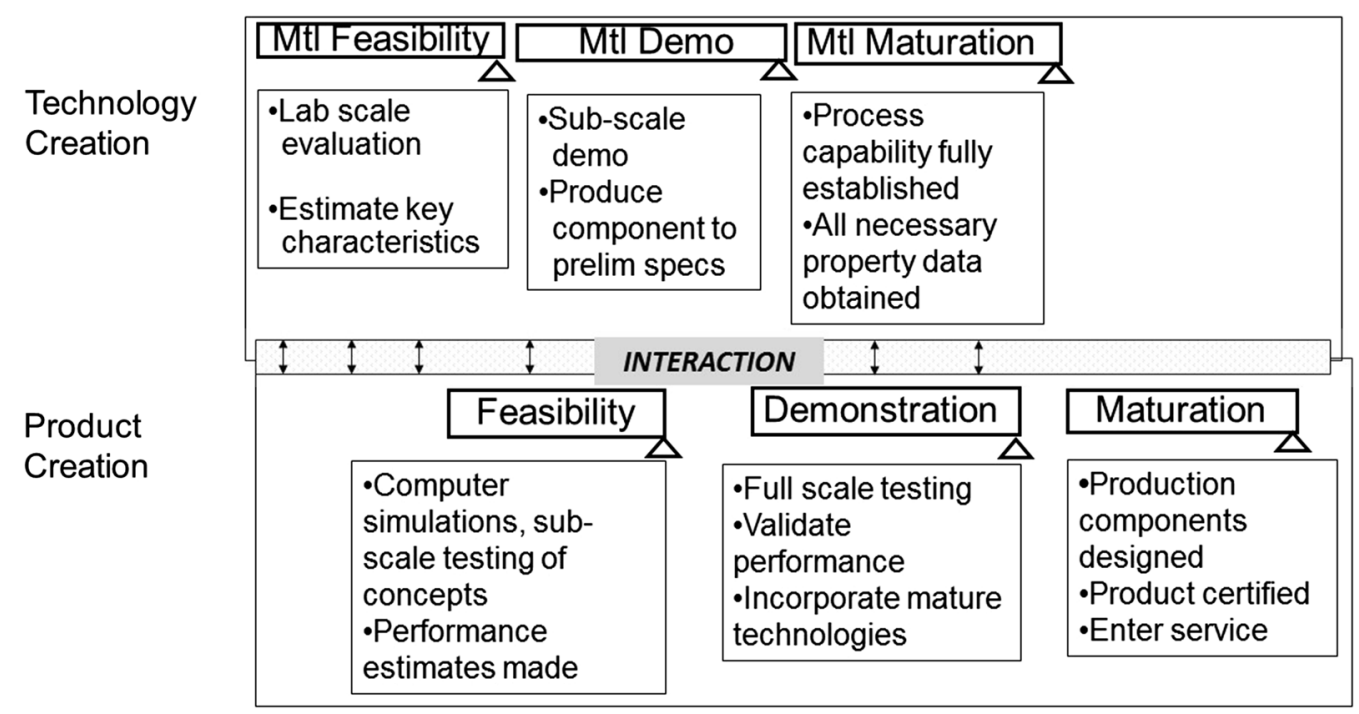

Fig. 3-Technology (material) and product development stages.

containing half the rhenium of the then standard GE René N5 alloy without compromising any capability; i.e., provide a form-fit-function material substitution.

During the materials strategy process for superalloy turbine blade materials, digital tools had been developed to predict turbine blade properties based on chemistry. These tools relied on a wealth of data from thousands of turbine blade tests of alloys with various chemistries performed by GE over a 25-year time period. These tools were employed to digitally evaluate chemistry iterations based on a design-of-experiments (DOE) analysis. The tools estimated strength, phase stability, and propensity to form undesirable phases. At the same time, several chemistries were selected to be cast into test specimens. Over a 3-month time period, the predicted data were able to be compared to the test data; there was reasonably agreement. These results added confidence that a new turbine alloy could be developed to replace the René N5 alloy with half the rhenium content (1.5 wt pct) with essentially the same properties as René N5. Figure 4 shows the principal high-level requirements that the new turbine blade alloy had to meet. ${ }^{[13]}$ During the subsequent 3 months, the models were exercised to demonstrate that it was possible to move directly from small heats to full-scale heats, skipping the time and cost of subscale heats. Full-scale heats of the material were ordered so that there was sufficient material to make a plethora of test specimens, and to initiate trial castings of production turbine blades. Ascertaining the castability of the new alloy was essential since redesigning all the casting tooling across all the engine lines would have taken considerable time and effort. Also, production processes such as machining, grinding, and coating were assessed on full-scale production blades. A few blades were inserted into a ground-test development engine to further assess performance under actual operating conditions.

Two years from the initial start of the program, the new alloy, known as René N515, was certified by the FAA, after engine testing in multiple engine lines. The

\begin{tabular}{|c|c|}
\hline Property / Item & Required René N515 Capabilities \\
\hline $\begin{array}{c}\text { Sustained Peak Low Cycle } \\
\text { Fatigue }\end{array}$ & Same as René N5 \\
\hline Creep Rupture & Same as René N5 \\
\hline Oxidation & Similar to René N5 \\
\hline Hot Corrosion & Similar to René N5 \\
\hline Low Temp. Low Cycle Fatigue & Similar to René N5 \\
\hline $\begin{array}{c}\text { Low Temp. Critical Crack } \\
\text { Growth Rate }\end{array}$ & Similar to René N5 \\
\hline Density & $<0.6 \%$ increase compared to René N5 \\
\hline Producibility & Similar to René N5 \\
\hline Manufacturing & No new processes required \\
\hline Repair & No new processes required \\
\hline
\end{tabular}

Fig. 4-Required material capabilities for alloy René N515.

traditional time required to develop a new turbine blade alloy was 4 to 6 years, and even longer in some cases. René N515 was incorporated into multiple applications across all the GE family of engines without requiring redesign of the turbine blade; slight adjustments in the casting tooling were required in some instances to avoid recrystallation defects. Figure 5 depicts the overall René N515 development timeline. The critical decision was authorizing full-scale heats of the material after the 6-month analysis period. ${ }^{[14]}$

René N515 is currently used in all high-performance GE Aviation engines. Each engine model has different temperatures and different temperature profiles. The mechanical properties of René N515 at all the different temperature conditions were slightly different than René N5 (it is slightly stronger than René N5 at some temperatures, and slightly weaker at some temperatures). A decision was made to assign a system engineer from the advanced design organization as co-leader of the development program to work with the design engineers from each engine model to continually 
evaluate the ability of René N515 to be a form, fit, and function replacement for $\mathrm{N} 5$ as the results from the extensive mechanical test program were completed. This organizational decision saved considerable programmatic time as the design engineers did not have to wait until milestone reviews to see the latest data and subsequently perform their analyses. The system engineer also sets the priorities for the sequence of engine models conversion to René N515.

The René N515 blades have performed comparable to René N5 blades in service. The price of rhenium has steadily declined as the usage of René N5 has declined; in January 2016 the price of rhenium was under $\$ 3000 /$ kg. ${ }^{[15]}$

\section{B. High Temperature Cast and Wrought Alloy, René 65}

Alloy 718, a cast and wrought alloy, is the most widely used material for turbine disks. However, it has limited temperature capability. As the performance and temperatures of aero-turbine engines have increased, alloy 718 did not have suitable mechanical strength as a first-stage turbine disk material. More highly alloyed superalloys with greater temperature capability were invented using powder metallurgy techniques. Disks made from this material require additional processing steps and thus are more costly: molten metal is atomized into powder; the powder metal is loaded into a can and then usually hot iso-statically pressed (HIP) and extruded to fully consolidate the material; and finally the disk is forged to shape from a slab cut from the extrusion in a special press that uses a slow deformation rate at an iso-temperature.

With the increase in the production volume of aero-engines, GE Aviation recognized that the suppliers would not have sufficient iso-forge capacity to produce all the needed disks within 5 to 10 years unless suppliers made major investments to acquire additional iso-forges, which cost millions of dollars. Since many of the applications of the powder alloy René 88DT (R88DT) did not need the full temperature capability of that alloy, the challenge was to re-examine producing a cast and wrought $(\mathrm{C} \& \mathrm{~W})$ version of R88DT that could replace at least half of the R88DT applications. This had been tried three times previously over the past 20 years. Those efforts were unsuccessful. Other alternative alloys were considered; however, none met all the strength requirements.

The latest computational tools were applied to evaluate chemistry changes to R88DT that would make

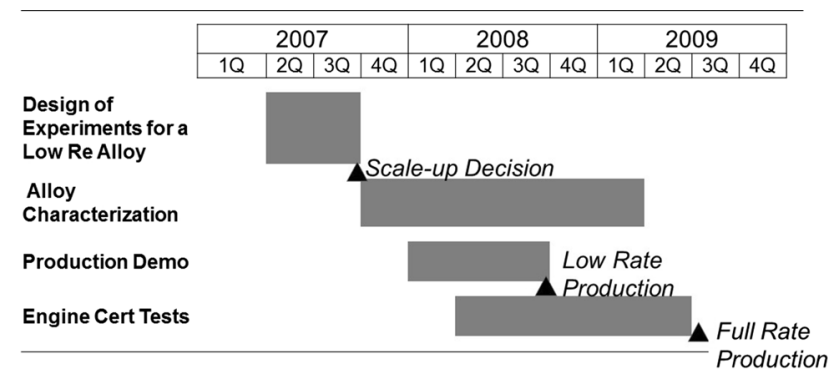

Fig. 5-René N515 development timeline. it processable by $\mathrm{C} \& \mathrm{~W}$, while still having sufficient high-temperature strength to replace some applications where R88DT was being used. Process and property modeling indicated that there was a narrow window that could be successful for the chemistry of interest. A decision was made to not use subscale trials - to go immediately to full scale. GE Aviation partnered with material supplier, ATI Allvac for this effort. ATI had made major investments in new furnace capability and a computer-controlled ingot breakdown facility that were capable of meeting the narrow processing window. The new alloy, René 65 (R65), was successfully cast and wrought. The material was then forged on conventional hot die presses to make full-sized disks. R65 is also being evaluated for large static structure applications.

R65 was conducted as an accelerated program. It was successfully completed in less than half the time that a typical turbine disk program has taken-the traditional timeline for a new disk alloy is 10 to 12 years; R65 development took 4 years from start to FAA qualification. Since it was aimed at applications in multiple engines, an unprecedented amount of production verification was undertaken. A typical disk development effort uses one or two forging suppliers; the R65 program used 10 forging suppliers. A total of 250 forgings were produced, covering the gamut from the small CF34 engine to the very large GE90 engine. A total of 4500 mechanical property tests were performed, consuming 1 million test hours. ${ }^{[16]}$

As was the case for the René N515 accelerated development program, there was a significant concurrency in the tasks for the R65 development program. A high-level development timeline is depicted in Figure $6{ }^{[17]}$ Since the team had high confidence in the selected chemistry, the majority of activity was focused on developing processing steps for making components of different sizes and shapes, and on mechanical testing using test specimens extracted from hardware produced using full-scale production processes.

GE Aviation has licensed the material to several other engine manufactures in order to build industrial capacity. In 2014, usage was approaching 450,000 kg per year.

\section{GO-FORWARD CHALLENGES}

The success with accelerated materials development programs demonstrates that reducing the timeline by half is possible. Experience to date points to two opportunity areas for further improvement in the development process: formation of high-performance teams, and continuing to improve the cyber computational tools and infrastructure.

The first challenge relates to further understanding and molding of high-performance teams. These teams are formed to achieve development program goals that have high impact. The team members really enjoy their experience serving on these teams, but sometimes are disappointed when the next team they join is not as high-performance. So the challenge is to have every team be high-performance, whether working on a high visibility development program or some other 
important, less visible task. This is very much a leadership challenge since the ingredients of instituting high-performance teams are known. Success with these teams builds additional successes. Over time, this will result in a cultural transformation in the workplace.

The second challenge addresses the need to continue to improve the digital tools and supporting infrastructure used by materials scientists and engineers. The use of modeling tools has increased year-over-year, and almost every materials development effort has made productive use of multiple digital tools.

There has been a non-linear increase in the number and use of digital models over the past 30 years. Early models focused on process modeling, such as forging, casting and heat treatment. Models were employed to help solve problems. Even though many tools used 2-dimensional finite elements, they provided useful insights. Soon models began to appear that predicted microstructure evolution based on thermodynamic knowledge. Over the past 10 years, models that predict properties, such as tensile, fatigue, and creep, have been developed. Some models employ heuristics while others are based on fundamental science. In addition, some codes are using 3-dimensional voxels to improve the accuracy of the analyses. To a large extent, the exponential increase in computer performance has made these improved models feasible for the materials community. Another important trend is the linking of models so that complex questions can be addressed without requiring significant human intervention. The composite materials area has been particularly effective in integrating models. As these models have improved and become more numerous, they have contributed significantly to the ability of shortening the materials development timeline without increasing the cost and risk of the development.

Suggestions of further improvements in digital tools include:

- Continue to improve computational models based on fundamental understanding of the phenomena being modeled, including databases that support the mod- els. Priority would be models with the following capabilities:

- Predicting microstructure evolution during processing.

- Predicting the effect of defects and microstructure variation on mechanical properties.

- Scaling mechanical properties obtained from subscale laboratory tests to those expected for fullsized components.

- Estimating the impact on mechanical properties as a result of the interaction of different degradation modes, such as corrosion, fatigue, and creep.

- Standard framework for linking tools together so that optimizations could readily be performed.

- Smooth integration of materials predictive models with design analysis tools.

A cyber infrastructure is needed that creates a low-maintenance collaborative materials ecosystem. Such an ecosystem, as notionally depicted in Figure 7, would curate digital models and the supporting databases. It would contain "user manuals" for the digital models so that less experienced users could quickly begin to use models of interest. It would serve as gatekeeper for those authorized to access the digital models and databases in line with a defined governance model, and employ the latest cyber security practices. ${ }^{[18]}$

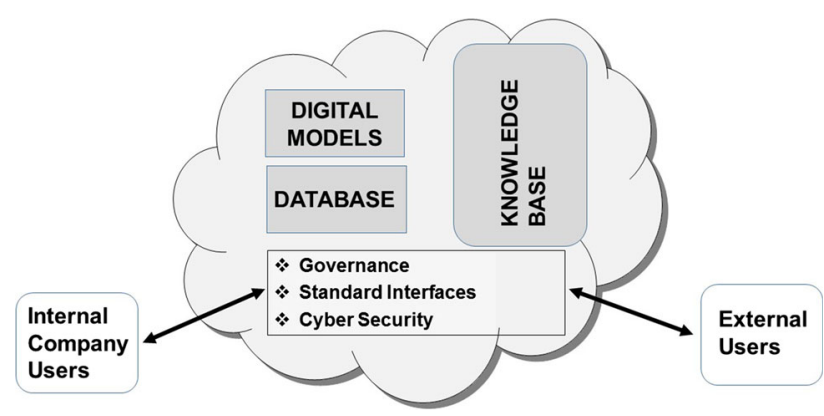

Fig. 7- Cyber collaborative infrastructure supporting materials development.



Fig. 6-René 65 development timeline. 
It would ease collaboration with those outside a company's proprietary walls, such as academia, suppliers, and partner OEMs. These access agreements would identify specific tools and databases that an authenticated user would be able to access. Such an ecosystem would also ensure that developed models and databases would be in a centralized repository rather than scattered in multiple locations, and would insure that users always had access to the latest version of the model and its associated database.

\section{CONCLUSIONS}

Over the ages, the materials community has contributed immensely to mankind's well-being. In this modern era, the expectation is that material advancements will play a major role in fulfilling societal needs at a faster pace. Rapidly improving digital computational tools and computer technology are making it possible to estimate performance of new materials in applications. Process models are meaningfully reducing the iterations required to achieve full-scale production as well as rapidly assessing the capability of new process technologies. However, the key to incorporation of materials into applications is satisfying enterprise needs, not just providing a superior materials solution.

Accelerated materials development programs can reduce the time for development by concurrency of tasks within the three technology development phases (Materials Feasibility, Materials Demonstration, and Materials Maturation) rather than accomplishing each phase faster. All critical development steps are completed. This scenario entails prudent assessment of the risks of going forward and planning for alternate approaches, especially since every development program inevitably experiences some surprises as the effort proceeds.

Faster development and product insertion of new advanced materials requires a more comprehensive strategy than digital computational tools, although these tools are a necessary analysis adjunct. Even if the digital tools were perfectly accurate, faster insertion is not a foregone conclusion. An enterprise perspective is strategically important as many factors influence the viability of a new material in a given application. Success with inserting materials indicates that these three strategic elements are necessary in addition to digital tools:

1. Forward-looking materials strategy - a feasible menu of material and process advancements that could significantly benefit a specific application. It is established by the inventive genius of materials experts, together with other experts, to explore and select new materials and process technology based on application value.

2. Robust management of materials development-a flexible, disciplined process for maturing and inserting new technology into a product in which the materials technology meets an identified need with an attractive value case.
3. Formation of small, focused high-performance teams to execute the development programs, composed of people skilled in innovation with the expertise needed to insert the new technology into an application. The team members are drawn from materials engineering, design engineering, manufacturing, systems engineering, etc.- people are the most critical ingredient in successfully conducting accelerated development programs.

Recent accomplishments with accelerated materials developments, such as developing a new single crystal turbine blade alloy, René N515 in 2 years and the new turbine disk alloy René 65 in 4 years at unprecedented speeds are testament to the viability of prudent accelerated materials development and demonstrate the potential of what is possible, realizing the long-standing dream of the materials community to respond quickly and expertly to satisfy critical product needs. The accelerated programs were undertaken to meet a critical business need by a certain insertion date; the timeline could not be achieved by following the conventional sequential development cycle. Also, success with inserting materials following the conventional timeline further reinforces the viability of applying digital tools in concert with the additional three strategic elements.

\section{ACKNOWLEDGMENTS}

This work was primarily funded by internal GE Aviation funds. The long-standing support of David L. Joyce, President and Chief Executive Officer, was essential to success and is gratefully acknowledged. Also, crucial was support from the Office of Naval Research (ONR), the Air Force Research Laboratory (AFRL), and the Defense Advanced Research Project Agency (DARPA) for programs that explored advanced ideas. Special recognition is due to John Polites and Mark Pearson of GE Aviation Engineering who enthusiastically supported and funded much of this work as they oversaw advanced engine developments, and to Steven Wax, who while at DARPA strongly encouraged the involvement of design engineers in DARPA's Accelerated Insertion of Materials program. And importantly, this work would not have been possible without the creative energy and dedication on the part of the men and women of GE Aviation's Materials and Process Engineering Department and GE Corporate's Global Research Laboratory.

\section{REFERENCES}

1. H. Brooks: Metall. Trans., 1972, vol. 3, pp. 759-68.

2. White House Office of Science and Technology Policy: Materials Genome Initiative for Global Competitiveness White Paper, June 2011.

3. J. Allison, D. Backman, and L. Christodoulou: JOM, 2006, vol. 58 (11), pp. 25-27.

4. National Research Council: Integrated Computational Materials Engineering: A Transformational Discipline for Improved Competitiveness and National Security, National Academy Press, Washington, 2008. 
5. National Research Council: Accelerating Technology Transition: Bridging the Valley of Death for Materials and Processes in the Defense Systems. The National Academies Press, Washington, 2004, p. 16

6. D.J. DeTurris and S.J. D'Urso: AIAA Aerosp Am, 2015, vol. 53 (10), pp. 32-36.

7. T.J. Kelly, M.J. Weimer: GE Aviation, Cincinnati, personal Communication, 2008.

8. Technology Readiness Assessment (TRA) Guidance, Prepared by the Assistant Secretary of Defense for Research and Engineering (ASD(R\&E)), April 2011.

9. Manufacturing Readiness Level (MRL) Deskbook version 2.0, Prepared by the Office of the Secretary of Defense Manufacturing Technology Program in collaboration with The Joint Service/Industry MRL Working Group, May 2011.

10. National Research Council: Accelerating Technology Transition: Bridging the Valley of Death for Materials and Processes in the Defense Systems. The National Academies Press, Washington, 2004, pp. 1-2.
11. J.R. Katzenbach and D.K. Smith: The Wisdom of Teams, Harvard Business School Press, Boston, 1992.

12. V.J. Russo and D.J. Black: The Splendid Leader, BookFactory, Dayton, 2008.

13. P.J. Fink, J.L. Miller, and D.G. Konitzer: JOM, 2010, vol. 62 (1), pp. 55-57.

14. D. Konitzer: GE Aviation, Cincinnati, personal communication, June 2014.

15. D. Konitzer: GE Aviation, Cincinnati, personal communication, Jan 72016.

16. M. Lasonde, J. Heaney, A. Powell, C. O'Brien, B. Bond: 8th International Symposium on Superalloy 718 and Derivatives, Wiley, Hoboken, pp. 67-77.

17. D .Mourer, K. Bain, M. Lasonde: GE Aviation, Cincinnati, personal communication, June 2014.

18. R. Irving: GE Global Research, Niskayuna, personal communication, Apr 2012. 